\title{
Emotional Intelligence Robotics to Motivate Interaction in e-Learning: An Algorithm
}

\author{
Dalia khairy ${ }^{1}$, Salem Alkhalaf ${ }^{2}$, M. F. Areed ${ }^{3}$, Mohamed A. Amasha ${ }^{4}$, Rania A. Abougalala ${ }^{5}$ \\ Department of Computer Teacher Preparation, Damietta University, Damietta, Egypt ${ }^{1,4,5}$ \\ Department of Computer Science, Qassim University, Alrass, Saudi Arabia ${ }^{2}$ \\ Department of Computer Science, Damietta University, Damietta, Egypt ${ }^{3}$
}

\begin{abstract}
The development of emotional intelligence robotics in the learning environment plays valuable support for social interaction among students. Emotional intelligence robots should be scalable to recognize emotions, appear empathetic in learning situations, and enrich the confidence with students for active interaction. This paper presents some related issues about integrating emotional intelligence robotics in E-learning such as its role and outcomes to motivate interaction during education and discover the main aspects of the emotional intelligence between humans and robots. This paper aims to determine the design requirements of emotional robots. Besides, this paper proposed a framework of educational Robotics with Emotional Intelligence in Learning (EREIL). EREIL consists of three main units; student emotions discovery, student emotions representation, and EREIL-Student Communication (RSC). In addition, it introduces a perception of EREIL working. In the future, this paper tries to merge more sensor devices and machine learning algorithms to integrate face analysis with speech recognition. Besides, it can add a persuasion unit in the EREIL robot to convince students with better learning choices to their abilities.
\end{abstract}

Keywords-Robotics; emotional intelligence; interaction; elearning; motivation; robot with emotional intelligence; machine learning algorithms; face analysis; speech recognition

\section{INTRODUCTION}

Educational Robotics(ER) has become increasingly common to handle possible future adaptation issues in Elearning. ER presents a deeply exciting learning environment in college, encouraging collaboration among learners, and realizing the generation of innovative experience in a reflexive method instructed by the teacher[1]. Recently, Teachers have often been struggling with keeping students' motivation and social interaction to the E-learning process. Student motivation is the backbone of the E-learning process because it affects student performance. This reflects the fact that ER can help to overcome the special educational needs of students such as Autism Spectrum Disorders(ASD)[2].

Furthermore, ER is an innovative field for students to build E-learning experiences [3][4]. It is related to both the observation and simple handling of a robot as well as more demanding tasks as the students are involved in planning, problem-solving, and decision making in relation to the robot's behavior, with the aim of developing creative thinking, the highest level of thinking [5]. ER for students with special educational needs includes the use of social robots for teaching various skills such as cognitive function, communication, and collaborative play[6][7].

Emotions have a complex structure to include specific social-cognitive dimensions to analyze things from the perspective of others and sharing other people's empathy[8][9]. Besides, emotion detection is a significant issue for special education, in two essential directions. The first regards students with special needs themselves who appear to have a deficiency in social perception and cognition[10]. The second direction regards children with insufficient mastering of social skills do not communicate and relate to others efficiently while they experience problems in playing, working, and learning with peers, which may well result in a certain degree of isolation [11].

Recently, emotional intelligence robots contribute to enhancing collaborative knowledge and individual and corporate self-efficacy[12]. In turn, they play a valuable role in promoting academic accomplishment, and cognitivemotivational features of learning in a student with intellectual disability increased significantly through the influence of robotics activities [13]. Furthermore, emotional intelligence robots enhance memory and attention for students with insufficient social experiences[14][15]. Besides, emotional intelligence robots encourage the processing of the complexity of human emotional expressions[16]. Thus, the field of Affective Computing requires to be updated and contributed with researches and experiences of emotional intelligence robots. Additionally, some practices in this field support improving creativity and sequential thinking for students[17].

The rest of the paper is organized as follows Section 2, highlights the emotional intelligence of humans and robots. In Section 3 the investigation of gender effects in students' perception is presented. Sections 4 and 5 look into age and educational robotics with educational intelligence and outcome of educational robotics with emotional intelligence in learning environment, respectively. Sections 6 and 7 display a framework of educational Robotics with Emotional Intelligence in Learning(EREIL); requirements, components, and an example of EREIL working. Section 8 concludes the paper proposing and future work to improve EREIL.

\section{EMOTIONAL INTELLIGENCE FOR HUMANS AND ROBOTS}

Robotics encourages integrative knowledge because of its inherent variation. Consequently, Robotics merges the learning among computational aspects, sensor devices, and 
expanding rapidly to emotional intelligence. Hence, it has the potential to excite and support talent by promoting technically-minded students. Robotics has particular value in this learning domain because it depends on computational thinking and has a powerful experimental domain for sensing, measuring, designing behavior, and emotional intelligence [18][19].

Emotional intelligence enriches the quality of the learning climate and improves academic performance. Besides, Emotional intelligence provides more knowledge to solve learning obstacles, support better learning organization, enhance personal growth, and handle stress through learning environments[20][21]. Emotional intelligence enhances richness with students and provides further versatility, adjustability, and skill at working in groups in the learning environment[22].

Emotional robots have played a vital role in the future of artificial intelligence when we focus on relational agents. Furthermore, relational agents present human social experiences, such as hand signs, position changes, and facial feelings, spoken words that sent fun, empathy, culture, and kindness[23][24]. Besides, emotional intelligence is an essential part of human intelligence and cognitive performance in the learning environment. Hence, emotional intelligence promotes the human connection with students and influencing their emotional progress[25].

The communication between students and an emotional robot influences the student's understanding of an emotional robot. Also, it concerns the student's performance during the interaction. Thus, students cooperate with an emotional robot that generates more significant advances in trust and works excellently on the assignment taught by an emotional robot. Besides, emotional robot converges on how to perceives and promotes emotions in particular communicative conditions. Furthermore, an emotional robot in learning environment affects to the emergence of team dynamics methods like; communication, collaboration, team administration[26].

The researches prove that the variation of the stimuli has a great role in human-robot interactions. The stimuli like; text, audio, video, and image. Text stimulus led to even higher perceived emotional intelligence of the student than the video, audio, and image stimuli, while the variation in the stimulitype does not affect the perceived emotional intelligence of the robot. Furthermore, the high emotional intelligence robots and humans as more trustworthy than the low emotional intelligence robots and humans. Besides, the content of the verbal interaction is essential for students' perceptions of emotional intelligence in both students and robots and not the tone of voice, posture, gesturing, or other bodily dynamics. The emotional robots in the learning environment might have to be endowed at least primary emotional intelligence capabilities. These capabilities enable them to focus on the students' emotional state, establish and maintain students' trust and build working relationships with them [27].

\section{StUdENTS' PERCEPTION OF GENDER EFFECTS IN DESIGNING ROBOTICS}

The emotional intelligence of students integrates gender parameters when making decisions and formed expectations in social interaction. In turn, that affects designing educational robotics[28]. Also, students have a positive attitude in their awareness, behavior, and perception towards the educational robotics have the same gender. That because the thought based on the same gender educational robotics is more believable, reliable, interactive, and engaging. Although the gender features offered in appearance more than objective parameters. For example, female students prefer educational robotics with pink lips, with a female name, and a female voice. Versus male students prefer educational robotics with gray lips, with a male name, and a male voice. As a result, this makes them feel more comfortable in social interaction, more desirable, more accepting, and more perfectly capable of performing a service task[28][29].

The female has high emotional intelligence than the male in human interactions. And the same goes for educational robotics. Consequently, students may lose their trust in male educational robotics. That indicates the essential for enhancing tools of male educational robotics to acquire them high emotional intelligence. Thus, disappearing gender-based differences in emotional intelligence [27].

Various strategies are adopted to facilitate optimal levels of perceived emotional intelligence and trust in educational robotics. For example, students will previously make decisions when discovering the gender of educational robotics regarding emotional intelligence and social interaction. As a solution, the design of educational robotics presenting emotional intelligence would be in a female voice. That is due to male educational robotics might disappoint expectations. However, for performing tasks that include sensitive social situations a male voice of educational robotics might be superior to reduce undesired results towards potential errors [30].

\section{Age AND EduCATIONAL Robotics With EDUCATIONAL INTELLIGENCE}

Age is relevant to expanded learning and practice experience. More youthful students manage to be limited exposure to while more experienced students seem to be extra excited with educational robotics with emotional intelligence [31]. This new trend should support various platforms, application interfaces to encourage a creative learning environment. Thus, these platforms seem to be quite promising for young students because they can reduce the age entrance for sharing in educational robotics with emotional intelligence and programming skills [32]. The integrated technologies and hybrid systems can facilitate engaging educational robotics with emotional intelligence for both young and older students. In turn, that can decrease cognitive content for students by engaging a new trend of learning through learning curriculum simultaneously [33]. 


\section{OUTCOMES OF EDUCATIONAL ROBOTICS WITH EMOTIONAL INTELLIGENCE IN E-LEARNING ENVIRONMENT}

The outcomes can de details as follows [34]:

- ER with EI assists to build an innovative learning environment and creates a valuable and attractive learning style.

- ER with EI integrates physical and mental experience for communication with the learning situations and their instruments.

- ER with EI enables students to discover by performing, managing conceptual theories, and integrating knowledge.

- ER with EI may encourage motivation for studying in courses that are commonly perceived by students as boring and not so exciting.

- ER with EI promotes knowledge spirit for both children and adult students who are further enthusiastic about robotics evolution.

- ER with EI adopted a facilitator learning environment for both students and professors. Consequently, professors prove high investment and concrete results in the use of EI in the studying environment.

- ER with EI provides more inclusive engagement in learning activities to retain students' concentration in the long-term and makes the professors' teaching further satisfying.
- ER with EI enriches the sufficient and motivation of the teaching method. Besides, it overcomes the boredom of traditional education methods.

\section{A FRAMEWORK OF EDUCATIONAL ROBOTICS WITH EMOTIONAL INTELLIGENCE IN LEARNING (EREIL)}

This section describes the proposed framework called EREIL. EREIL aims to motivate interaction among students in the learning environment. EREIL improves to assist students in promoting their social connections during the daily performance in the learning environment. This section divides into two main subparts: the design requirements of EREIL and the components of EREIL.

\section{A. The Requirements of EREIL}

The requirements of EREIL can be divided into three types; needs determination \& analysis, design, and technology.

1) Needs determination and analysis requirements: These requirements analyze the steps to integrate EREIL in elearning environment as seen in Fig. 1.

2) Design requirements: These requirements regarding design principles of EREIL, the requirements explained in Fig. 2.

3) Other requirements: These requirements can be represented into three requirements. First, encouraging innovative teaching methods: It includes adapting teamwork and critical thinking. Second, developing programmable systems: It includes focusing on enriching observation, analysis, supporting modeling and simulation. Third, adopting project-based learning: It includes learning-based problem solving and adapting cultivating collaboration skills.

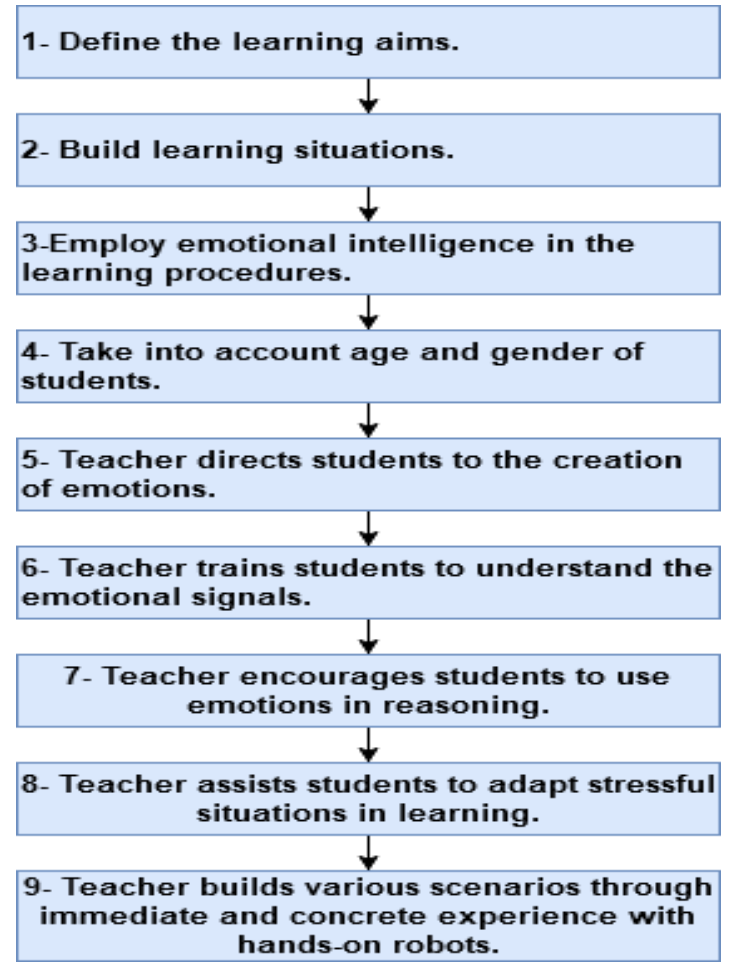

Fig. 1. Needs Determination and Analysis Requirements of Emotional Intelligence Robots. 


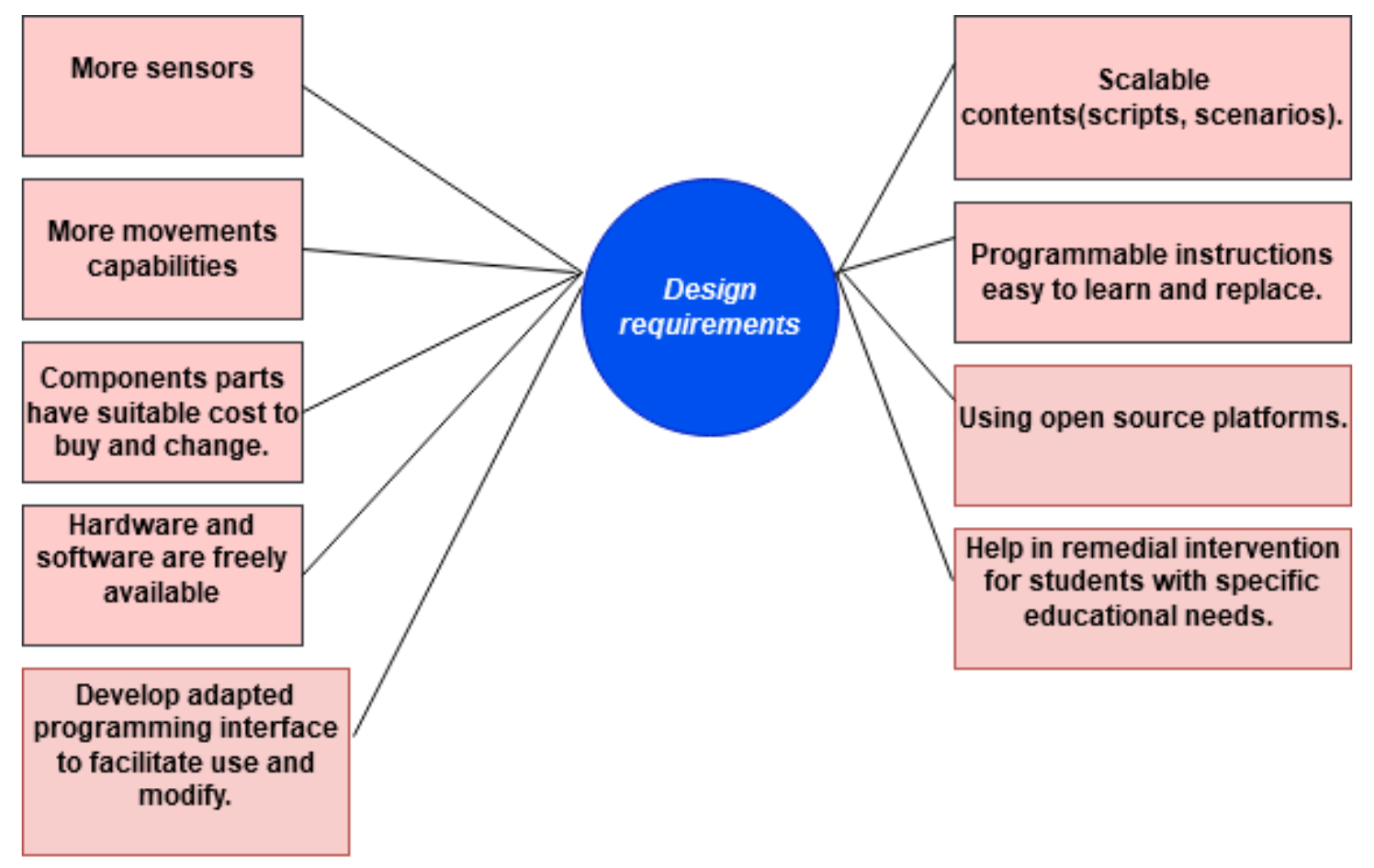

Fig. 2. Design Requirements of Emotional Intelligence Robots.

\section{B. The Components of EREIL}

EREIL consists of three main units; student emotions discovery, student emotions representation, and EREILStudent Communication (RSC) (see Fig. 3). It is clear that the two units responsible for discovering, implementing, and processing, and representing emotions. Furthermore, the third unit enhances the student practice and supplies a running visible interface to the EREIL robot.

EREIL can implement the following essential characteristics:
- It determines the common sentiment of a collection of students.

- It shows student determined sentiments according to the emotional moods of the students.

- It helps students supporting the learning schedule.

- It stores learning tasks to tell students to perform them at a determined duration.

- It convinces students by providing them reasons to confirm suggested learning activities according to their learning profile and individual abilities.

- It recognizes the emotions of several students.

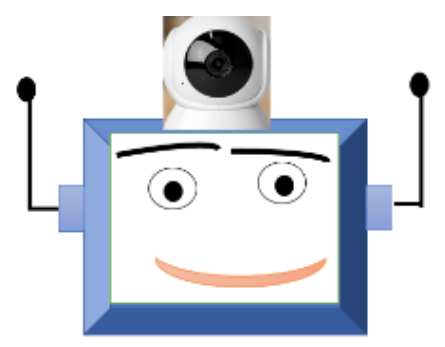

\begin{tabular}{|c|c|c|}
\hline $\begin{array}{l}\text { Student emotions } \\
\text { discovery }\end{array}$ & $\begin{array}{l}\text { Student emotions } \\
\text { representation }\end{array}$ & $\begin{array}{c}\text { EREIL-Student } \\
\text { Communication(RSC) }\end{array}$ \\
\hline $\begin{array}{l}\text { 1- face print analysis } \\
\text { 2- Speech identifier }\end{array}$ & $\begin{array}{l}\text { Identify emotions } \\
\text { happiness, sadness, fear, } \\
\text { surprise, anger,neutral, } \\
\text { disgust, and worry }\end{array}$ & 2- Tasks reminder \\
\hline
\end{tabular}

Fig. 3. Components of EREIL Robot. 
1) Student emotions discovery: The discovery process of students' emotions plays an essential role in social interaction in the learning environment. Thus, the implementation of emotions discovery helps students to practice sharing, interaction, and collaboration. Also, it can be useful to recommend an adaptive response or recommend modifications for a better response.

EREIL is a proposed framework to support sensing devices, recognize and represent some factors of student performance. EREIL supports the student's body signals (i.e., emotions, speech level, gestures, etc.) to recognize these communications performed in the learning environment. EREIL discovers student's body signals through contacting eyes, gestures, face analyzing, and voice recognition. Through this discovery, EREIL can determine student identification. Besides, it is important to increase sensors that support EREIL to obtain students identification. Although sensor devices are not sufficient in EREIL, it is necessary to support artificial intelligence (AI) fields. AI allows to analysis and training of the collected raw data from sensor devices. With AI potentials, we can use face identification, speech recognizing, interpret natural language, and emotional discovery.

a) EREIL for student's determination and sentiment analysis: EREIL determines the student identification and other students who can share the learning activities with him. It aims to select suitable machine learning techniques that can contribute to students' face recognition. This process should be agile and easy to decrease the training time and not confuse the student. Furthermore, the student face recognition process depends on converting face to vectors with special determinates. Every face has specific landmarks that can be measured, such as the distance between the eyes, the length of the jaw line, the shape of the eyebrows, and more. Together, they create a unique faceprint that can later be compared with other students until a match is found, thus recognize student.

EREIL allows classifying emotions through a deep learning machine to analyze students' sentiments. EREIL classifies students' emotions to happiness, sadness, fear, surprise, anger, neutral, disgust, and worry. Besides, EREIL can use the web service to train and examine students' emotions because this procedure can be a difficult and high cost if it computes on EREIL.

b) Emotional web assistance for EREIL: As mentioned, to reduce the overload of computational analysis on EREIL for determining students' identifications and emotions, EREIL depends on the webserver. This web assistance supports EREIL to recognize students' faces, analyze emotions, and recognize the sharing emotions among a group of students. EREIL encourages the students to optimize the decisionmaking in communication with other students and enhance taking decisions regarding cooperating and sharing learning activities.

Nevertheless, if EREIL does not know the student identification. EREIL displays a collection of questions to promote communication with the student for discovering the student's name, face, and identification. Then, EREIL creates a conversation with the student to recognize more information about him and stores the new data. Furthermore, EREIL separately recognizes students in groups. In other words, EREIL recognizes each student alone and takes assistance from a web server for analyzing face. Then, if EREIL discovers another unknown student, the same process will repeat. Also, recognizing the emotions of a students' group allows EREIL to understand what the sensitive mood of the group is. Consequently, EREIL tells the student to perform alone if this emotion is further away from his interests.

2) Student emotions representation: EREIL contributes to understanding emotions for students. And that is in turn influences on changing students' reactions. As a result, it is essential for EREIL to represent expressions of its own emotional situation. Thus, these representations would be directly benefited the interaction with students. So, EREIL uses sensors devices to recognize the learning environment and use this knowledge to express its emotional situation.

EREIL can express emotions by sensors of its face like contact eyes to start and manage communication. Looking at student's eyes during speech attracts attention and integrates interaction during the speech.

Face tracking technology can assist in face detection. While the student moves his eyes towards learning activities, EREIL can follow this moving to start and maintain eye contact. Thus in turn encourages the student's attention and promotes interaction. Besides, this information enriches EREIL to start of dialog at a suitable time, greet the student with a friendly smile. Furthermore, EREIL keeps eyebrows and mouth to express different emotions. Also, eye contact contributes to measure engagement between students and EREIL, better understand students' demands, and produce more appropriate information.

3) EREIL-Student Communication (RSC): The student's communication is promoted with EREIL using RSC. RSC is the unit is responsible for enhancing the student practice in learning activities and supplying a running visible interface to the EREIL robot. RSC is a supporter for student to increase learning motivation through remembered daily learning assignments and proposing activities. Besides, RSC explains new activities to expand the learning experiences of students and recommends with external learning sources to encourage rounded learning by integrated the practical exercises with academic learning.

RSC consists of four subunits: 1) student identification, 2) tasks reminder, 3) activities suggestion, 4) direct sending.

- Student identification: This subunit stores the personal data and learning progress information of each student. It RSC aims to develop the students' learning aspects. Hence, storage the students' learning activities, interests, preferences, and the right time to perform them. However, RSC needs the personal information; name, address, age, parents, closer friends, learning style, and preferred subjects to create recommendations and advice related to the personal environment. 
- Activities suggestion: This subunit decides and recommends activities to the student based on personal data and interests. It aims to keep students in active mind and continuous research to reach rounded learning, e.g., use external video, audio, documentation films, reading reference books to connect academic learning with practical needs, engage other students in learning gamification. Besides, if closer students of the student are comprised a group on RSC, in turn RSC will recommend activities and learning games suitable to shared interests and in appropriate time to all of them.

- Tasks reminder: This subunit displays the activities, lessons, assignments of daily tasks to students. EREIL keep these learning tasks with date and time to tell each student about its schedule.

- Direct sending: This subunit presents a means to send information directly to EREIL through its touchscreen. When a student wants to send information to EREIL. Besides, EREIL uses direct sender to create an interactive situation among students and respond to students' decisions. On the other hand, a student can send a message through the visual interactive screen to use EREIL sensors devices to catch information. It is essential to teach EREIL, by keeping interaction with the students.

Fig. 4 shows Algorithm 1 for how EREIL discovers the student's face. EREIL greets the student when EREIL discovers the student's face. Besides, it explains the EREIL behavior with unknown student. EREIL does not detect the student's face. EREIL will ask the student about his name, capture a photo, and stores it.

Besides, Fig. 5 shows Algorithm 2 for how EREIL reminds the student of the scheduled tasks. For example, EREIL reminds the student of the Science Lab time at 1:00 PM by displaying on the touch screen and wait for the student's response.

Furthermore, Fig. 6 shows Algorithm 3 for the activity suggestion from EREIL to the student. For example, EREIL suggests activity "play volley ball by displaying on the touch screen and wait for the student's response". In addition, Fig. 7 presents Algorithm 4 for direct sending between EREIL and student.

\section{Algorithm 1: How EREIL discovers the student's face}

\section{Step1: Start}

Step2: EREIL senses the existence of someone.

Step3: EREIL opens the camera to discover a student.

Step4: EREIL compares the captured photo of the student with stored photos of the students.

Step5: If the captured photo matches any of the stored photos Then

Appear a greeting message on a touchscreen

"Welcome + Student's name"

Step6: Else EREIL appears a message on a touchscreen

"Who are you?"

Step7: The student writes his name on a touchscreen.

Step8: EREIL takes a photo to store it and to detect the student later.

Step9: End

Fig. 4. Algorithm1 for Discovering the Student's Face. 


\section{Algorithm 2: How EREIL reminds the student of the scheduled tasks}

\section{Step1: Start}

Step2: EREIL watches time.

Step3: EREIL keeps in touch with scheduled tasks.

Step4: EREIL compares between the current time and time of scheduled tasks.

Step5: If the current time matches any of the scheduled tasks Then EREIL alarms a student by displaying on a touchscreen.

Step6: Appear a message" Hi + student name". It is 1:00 PM. You have to go to Science Lab.

Step7: EREIL presents two choices on a touch screen.

Step8: If the student accepts to go the task Then

Student will click Let's go button on a touch screen.

Fig. 5. Algorithm 2 for Tasks Reminder using EREIL.

\section{Algorithm 3: How EREIL suggests activities to the student.}

\section{Step1: Start}

Step2: EREIL watches time.

Step3: EREIL keeps in touch with activities suggestion.

Step4: EREIL compares between the current time and time of activities suggestions.

Step5: If the current time matches any of the activities suggestions Then EREIL alarms a student by displaying on a touchscreen.

Step6: Appear a message" $\mathrm{Hi}+$ student name". It is 3:00 PM. Let's play volleyball.

Step7: EREIL presents two choices on a touch screen.

Step8: If the student accepts to practice activity Then

Student will click Let's go button on a touch screen.

Step9: Else student will click Another suggestion button on a touch screen.

Step10: If the student clicks Another suggestion button Then go to Step 6 with changing activity.

Step11: Else go to Step 12.

Fig. 6. Algorithm 3 for Activities Suggestion using EREIL. 


\section{Algorithm 4: Direct sending between EREIL and the student.}

\section{Step1: Start}

Step2: Student requests EREIL to send a message.

Step3: EREIL appears touch screen for direct sending.

Step4: Student writes the request on EREIL touch screen.

\section{Ex.: Student writes "suggest me an external resources about the human digestive} system".

Step5: EREIL appears a message "Wait a few seconds. I will display some videos".

Step6: Student watches to videos.

Fig. 7. Algorithm 4 for Direct Sending using EREIL.

\section{VII.PERCEPTION OF EREIL WORKING: AN EXAMPLE}

To explain the performance of EREIL, this section displays an example that illustrates the various processes made by EREIL as an emotional robot recommender in the learning environment.

The EREIL will communicate with students by recognizing them, identifying their emotions, and recommending actions and activities in the learning environment.

The perception of EREIL performance as seen in Fig. 8:

1) EREIL starts performance when seeing a student or group of students.

2) EREIL starts a dialogue with the student and ask him some question to detect the identification. This case when EREIL does not recognize the student.

3) Besides, EREIL captures the student's face, analyzes the coordinates of the face $(x, y)$, and encoding the photos to recognize identification.

Note: The camera of EREIL will locate in the center of EREIL's face to easily capture the student's face. Furthermore, EREIL periodically captures students' faces and stores them with learning progress, personal profiles, interests, activities, and schedule.

4) If EREIL recognizes the student's face. Then EREIL will greet the student with his name.

5) When EREIL knows the student, it will discover his emotion. If the EREIL identifies more than one student in the same group of students in the capturing, the manner is returned for each face, beginning the computation of engagement emotion.

6) As soon as the students' emotion is detected, EREIL will show empathy with the student. Also, it can move his eyes, mouth, and eyebrows. Besides, EREIL can suggest some learning activities and control its sensors devices to suitable for student emotion.

7) After that, EREIL reminders some tasks from the learning schedule. Then, EREIL suggests the interested students and closest to the student.

8) Furthermore, EREIL can suggest some activities and present some external learning sources as, books, video, virtual labs, and serious games.

Note: In step7 and step8, EREIL begins an active dialog with students, detects their emotions, and chooses the appropriate activities and tasks.

9) During the previous steps, EREIL can receive direct messages through the direct sender subunit and send responses to students.

10)If EREIL finds a student alone or a student refuses the suggested activity, EREIL can present joyful messages as an attempt to engage him in the learning environment again. Besides, EREIL finds a way to personalize interactions with students. EREIL can stores valuable information gathered during their previous interactions, such as their favorite learning activities, preferred external sources, closest students, and academic learning progress. 


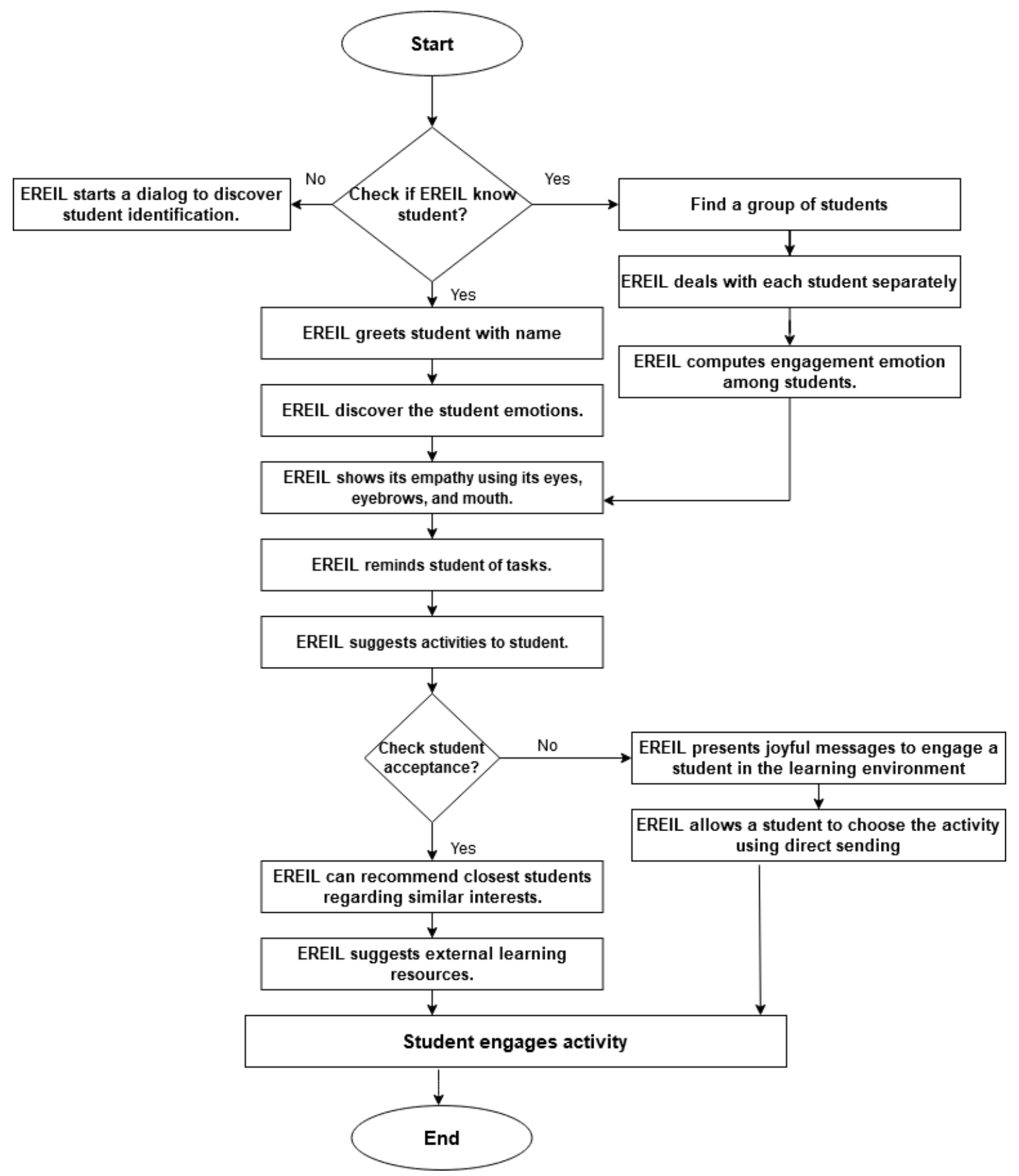

Fig. 8. Flowchart of an Example of EREIL Working.

\section{CONCLUSION AND FUTURE WORK}

This paper discussed educational robotics with emotional intelligence as an assist to motivate interaction in the learning environment. These robots can overcome the special educational needs of students such as autism spectrum disorders. Also, emotional intelligence robots can help students who have a loss in social communication and perception, mental impairment of spoken and non-spoken communication, presence of personal isolated interests, and students who reach the point of social alienation. It presented a proposed framework EREIL, as a student supporter for social interaction in the learning environment. Furthermore, it presented the main requirements to build emotional intelligence robots as requirements of needs determination, designing, and technology. Besides, it presents proposed EREIL three main units: student emotions discovery, student emotions representation, and EREIL-Student Communication (RSC). The first two units are responsible for discovering, implementing, and processing, and representing emotions. The third unit enhances the student practice and supplies a running visible interface to the EREIL robot. Hence, the third unit is divided into four subunits: student identification, tasks reminder, activities suggestion, and direct sending. Additionally, it presented an example of EREIL working. 
The existing work agrees with the following related works. The author in [35] introduced a robot that can understand and express emotions in voice, gesture, and gait using a controller trained only on voice. Besides, [5] proposed a novel algorithm for emotional intelligence robots to recognize human emotions from daily-life gestures. They used machine-learning techniques to automatically infer human emotions with high accuracy. Moreover, [8] showed that the importance of emotional intelligence has a significant effect on employee retention and performance, whereas artificial intelligence plays a significant moderating role in employee performance. Additionally, [13] presented human-robot interaction and how to recognize human emotional states. Also, it explained emotion levels from users are detected through vision and speech inputs.

As future work, we hope to execute a practical case study of the EREIL robot and enhance discovering emotions. It can be implemented by adding more sensor devices and machine learning algorithms to integrate face analysis with speech recognition. Another aspect that can be presented is to store the expert teachers' opinions of students for tracking their instructions in learning activities and their opinions in students' learning progress. Besides, it can add a persuasion unit in the EREIL robot to convince students with better learning choices to their abilities. Additionally, the persuasion unit can provide students with suggestions related to their learning.

\section{REFERENCES}

[1] Khairy, D., Abougalala, R. A., Areed, M. F., \& Atawy, S. M. (2020). Educational Robotics Based On Artificial Intelligence And ContextAwareness Technology: A Framework. Journal of Theoretical and Applied Information Technology, 98(13), pp. 2227- 2239.

[2] Amo, D., Fox, P., Fonseca, D., \& Poyatos, C. (2021). Systematic Review on Which Analytics and Learning Methodologies Are Applied in Primary and Secondary Education in the Learning of Robotics Sensors. Sensors, 21(1), 153.

[3] Misirli, A., \& Komis, V. (2014). Robotics and programming concepts in Early Childhood Education: A conceptual framework for designing educational scenarios. In Research on e-Learning and ICT in Education (pp. 99-118). Springer, New York, NY.

[4] Alimisis, D. (2013). Educational robotics: Open questions and new challenges. Themes in Science and Technology Education, 6(1), 63-71.

[5] Loghmani, M. R., Rovetta, S., \& Venture, G. (2017, May). Emotional intelligence in robots: Recognizing human emotions from daily-life gestures. In 2017 IEEE International Conference on Robotics and Automation (ICRA) (pp. 1677-1684). IEEE.

[6] Krägeloh, C. U., Bharatharaj, J., Sasthan Kutty, S. K., Nirmala, P. R., \& Huang, L. (2019). Questionnaires to measure acceptability of social robots: a critical review. Robotics, 8(4), 88.

[7] Hughes-Roberts, T., Brown, D., Standen, P., Desideri, L., Negrini, M., Rouame, A., ... \& Hasson, C. (2019). Examining engagement and achievement in learners with individual needs through robotic-based teaching sessions. British Journal of Educational Technology, 50(5), 2736-2750.

[8] Prentice, C., Dominique Lopes, S., \& Wang, X. (2020). Emotional intelligence or artificial intelligence-an employee perspective. Journal of Hospitality Marketing \& Management, 29(4), 377-403.

[9] Ornaghi, V., Brockmeier, J., \& Grazzani, I. (2014). Enhancing social cognition by training children in emotion understanding: A primary school study. Journal of Experimental Child Psychology, 119, 26-39.
[10] Damiano, L., Dumouchel, P., \& Lehmann, H. (2015). Artificial empathy: An interdisciplinary investigation.

[11] Ziouzios, D., Ioannou, M., Ioanna, T., Bratitsis, T., \& Dasygenis, M. (2020). Emotional Intelligence and Educational Robotics: The Development of the EI-EDUROBOT. European Journal of Engineering Research and Science.

[12] Kanda, T., Shimada, M., \& Koizumi, S. (2012, March). Children learning with a social robot. In 2012 7th ACM/IEEE International Conference on Human-Robot Interaction (HRI) (pp. 351-358). IEEE.

[13] Erol, B. A., Majumdar, A., Benavidez, P., Rad, P., Choo, K. K. R., \& Jamshidi, M. (2019). Toward artificial emotional intelligence for cooperative social human-machine interaction. IEEE Transactions on Computational Social Systems, 7(1), 234-246.

[14] Fridin, M., \& Yaakobi, Y. (2011, May). Educational robot for children with ADHD/ADD. In Architectural Design, In. Conf on Computational Vision and Robotics.

[15] Caci, B., D’Amico, A., \& Chiazzese, G. (2013). Robotics and virtual worlds: An experiential learning lab. In Biologically Inspired Cognitive Architectures 2012 (pp. 83-87). Springer, Berlin, Heidelberg.

[16] Hudson, S. (2020). Artificial intelligence, Cognitive Robotics and Human Psychology. DO-10.13140/RG. 2.2. 20153.52323.

[17] Vlachos, E., \& Schärfe, H. (2012, October). Android emotions revealed. In International Conference on Social Robotics (pp. 56-65). Springer, Berlin, Heidelberg.

[18] Siciliano, B., \& Khatib, O. (Eds.). (2016). Springer handbook of robotics. Springer.

[19] Benitti, F. B. V. (2012). Exploring the educational potential of robotics in schools: A systematic review. Computers \& Education, 58(3), 978988.

[20] Salminen, M., Hamari, J., \& Ravaja, N. (2021). Empathizing with the End User: Effect of Empathy and Emotional Intelligence on Ideation. Creativity Research Journal, 1-11.

[21] Krakovsky, M. (2018). Artificial (emotional) intelligence. Communications of the ACM, 61(4), 18-19.

[22] Kim, Y., \& Baylor, A. L. (2016). Based design of pedagogical agent roles: A review, progress, and recommendations. International Journal of Artificial Intelligence in Education, 26(1), 160-169.

[23] Yonck, R. (2020). Heart of the machine: Our future in a world of artificial emotional intelligence. Arcade.

[24] Jeon, M. (2017). Emotions and affect in human factors and humancomputer interaction: Taxonomy, theories, approaches, and methods. In Emotions and affect in human factors and human-computer interaction (pp. 3-26). Academic Press.

[25] Veletsianos, G., \& Russell, G. S. (2014). Pedagogical agents. In Handbook of research on educational communications and technology (pp. 759-769). Springer, New York, NY.

[26] Fan, L., Scheutz, M., Lohani, M., McCoy, M., \& Stokes, C. (2017, August). Do we need emotionally intelligent artificial agents? First results of human perceptions of emotional intelligence in humans compared to robots. In International Conference on Intelligent Virtual Agents (pp. 129-141). Springer, Cham.

[27] Chita-Tegmark, M., Lohani, M., \& Scheutz, M. (2019, March). Gender effects in perceptions of robots and humans with varying emotional intelligence. In 2019 14th ACM/IEEE International Conference on Human-Robot Interaction (HRI) (pp. 230-238). IEEE.

[28] Tay, B., Jung, Y., \& Park, T. (2014). When stereotypes meet robots: the double-edge sword of robot gender and personality in human-robot interaction. Computers in Human Behavior, 38, 75-84.

[29] Devillers, L. (2020). Social and emotional robots: useful artificial intelligence in the absence of consciousness. In Healthcare and Artificial Intelligence (pp. 261-267). Springer, Cham.

[30] Lohani, M., Stokes, C. K., Oden, K. B., Frazier, S. J., Landers, K. J., Craven, P. L., ... \& Macannuco, D. J. (2017, March). The impact of nontechnical skills on trust and stress. In Proceedings of the Companion of the 2017 ACM/IEEE International Conference on Human-Robot Interaction (pp. 191-192). 
[31] Sapounidis, T., \& Alimisis, D. (2020). Educational Robotics for STEM: A Review of Technologies and Some Educational Considerations. Science and Mathematics Education for 21st Century Citizens: Challenges and Ways Forward; Nova Science Publishers: Hauppauge, NY, USA, 167-190.

[32] Sapounidis, T., Stamelos, I., \& Demetriadis, S. (2016). Tangible user interfaces for programming and education: A new field for innovation and entrepreneurship. Advances in Digital Education and Lifelong Learning, 2, 271-295.

[33] Sapounidis, T., \& Demetriadis, S. (2016, November). Educational robots driven by tangible programming languages: A review on the field. In International Conference EduRobotics 2016 (pp. 205-214). Springer, Cham.

[34] D'Amico, A., Guastella, D., \& Chella, A. (2020). A Playful Experiential Learning System With Educational Robotics. Frontiers in Robotics and AI, 7, 33.

[35] Lim, A., \& Okuno, H. G. (2014). The mei robot: towards using motherese to develop multimodal emotional intelligence. IEEE Transactions on Autonomous Mental Development, 6(2), 126-138.

\section{AUTHORS' PROFILE}

Mohamed A. Amasha, was born in Damietta Egypt, in 1970. He is professor in the application of computer. He worked as a vice dean the faculty of computer and information Damietta university. He is also a manager of $\mathrm{E}-$ portal at Damietta University. He works as a lecturer at Damietta University, Faculty of specific education, Computers Dept., With over 11 years of experience in Qassim university KSA, He has published in A.U.C in Egypt, IJACSA, IJORCS, Springer, IEEE.
Marwa F. Areed, is now a lecturer at Damietta University, Faculty of Engineering, Computers \& Systems Dept., with over 13 years of experience in Mansoura University Faculty of Engineering from 2000 till 2017 and over three years in Taibah University, Computer Science Collage, Medina, KSA She received M.Sc. (2003) and Ph.D. (2009) in Computer Engineering, both from Faculty of Engineering, Mansoura University. Her scientific interest includes Data Security in clouds, image compression, digital watermarking \& steganography, Cloud Computing, Clustering Algorithms, Sentiment analysis and wireless networks. She has published in INFO2008 in Cairo, (International journal of computer Application 2012, international Journal of Engineering \& technology 2014, Simulation Modeling Practice \&Theory 2018 and finally in Journal of the International Measurement Confederation (IMEKO).

Dalia Khairy was born in Egypt, Damietta, in 1985. She is a lecturer in the application of computer in education. He works as lecturer, in Damietta University, Egypt.

Raian A. Abougalala, was born in Egypt, Damietta, in 1982. She is a lecture in the application of computer in education. She works as lecture, in Damietta University, Egypt. She has published in Springer.

Salem Alkhalaf, is an Associate Professor in Computer department, College of Science and Arts in Al-Rass, Qassim University. He graduated Bachelor of Education degree in Computer Since from the Department of Computer, Teachers College (Riyadh) in 2003, Also he graduated with Honors degree. And he graduated the Master of ICT from Griffith University (Brisbane, Australia) in 2008. And, he graduated the $\mathrm{PhD}$ in. 